\title{
REVIEW
}

\section{Research on Diversity in Youth Literature, edited by Sarah Park Dahlen and Gabrielle Atwood Halko}

\author{
TERRI SUICO \\ SAINT MARY'S COLLEGE
}

One of the most heartening trends in children's and young adult literature is the greater attention that diversity and representation have received. Two prominent examples of this include We Need Diverse Books, which evolved from a Twitter movement to a nonprofit organization and emphasizes the need for more representation in books, and \#DisruptTexts, which encourages teachers to reconsider the literary canon and common classroom texts "in order to create a more inclusive, representative, and equitable language arts curriculum" ("What is \#Disrupt Texts?," n.d.). Along with these discussions have come some changes in publishing. The Cooperative Children's Book Center (2019) reported receiving 3,644 books by and about people of color and first/native nations in 2018, a 21\% increase since 2008. However, there is still a need for growth, particularly in relation to books by authors from diverse backgrounds (Erlich, 2017), which has not grown at the same rate.

With this increase in books by and about diverse people comes the need for scholarship that goes beyond the numbers of the books published and instead assesses the content. For instance, what themes and ideas are found in these texts? What groups are they representing and addressing? How sound are the representations? Themed issues of academic journals, such as this one, can be part of the conversation, but more opportunities to highlight research on diverse books are needed. Fortunately, Research on Diversity in Youth Literature (RDYL) has provided a much-needed venue for this work. This biannual peer-reviewed journal, co-edited by Sarah Park Dahlen and Gabrielle Atwood Halko, just started publishing in 2018, but it has already had a significant impact on the conversation surrounding the diversity found in children's and young adult literature. 
From its first appearance, RDYL has distinguished itself from other scholarly publications. As the editorial board statement for the first issue notes, one of the main goals of RDYL is to provide "a space to foster intellectually rigorous scholarship that may or may not fit conventional molds" (Slater, 2018, p.1). The “About This Journal” page and the editors' introduction to the inaugural issue elaborate on this by providing insight into the journal's founding. Besides the gap in scholarly publications dedicated to examining diversity in children's and young adult literature, Dahlen and Halko, along with several other scholars interested in activism (Dahlen and Halko, 2018), determined that there was a need for "a new space for scholarship, one that would actively seek work that was frequently deemed 'too political' or 'not scholarly enough' by established journals” (p.2). This led to the creation of RDYL, which is currently hosted on St. Catherine University's openaccess platform.

With its foundation rooted in the study of diversity and representation in children's and young adult texts, RDYL has themed issues once a year, which allows for a more specific focus within the broad subject of diversity and results in a multifaceted consideration of a particular topic. For the introductory issue, Dahlen and Halko selected the fitting theme “\#OwnVoices Scholars Respond to 'Mirrors, Windows, and Sliding Glass Doors," which positions the journal as building upon previous examinations of representations while also moving the conversation forward. Based on Dr. Rudine Sims Bishop’s article “Mirrors, Windows, and Sliding Glass Doors,” contributors responded to Bishop's assertions that books can and should allow readers to see themselves in books (mirrors) as well as allow readers to see other worlds (windows) and to interact with these worlds (sliding glass doors). Besides considering and reacting to Bishop's ideas, Dahlen and Halko further underscore RDYL's vision by featuring submissions by \#OwnVoices scholars, thus emphasizing not just diversity in content but also in the contributors and valuing the importance of the contributors' identities when it comes to engaging with their research.

The result is a cohesive and thought-provoking issue with articles that explore the different ways \#OwnVoices researchers read and respond to the windows, mirrors, and doors they found in works meant for children and adolescents. Topics range from an examination of the mirrors Crinstina Rhodes, a Chicana scholar, discerns in Matt de La Peña's Mexican Whiteboy to considering the benefits and limitations that queer Christian young adult texts offer in relation to Bishop's mirrors, windows, and doors model. Other standouts include Michelle H. Martin and J. Elizabeth Mills's (2018) analysis of the crossover scholarship framework, which is "a first step in 
confronting the long-term problem of diversifying the field” (p.2) of academia by helping scholars "gain more cultural competence” (p.2) as well as E. Sybil Durand and Marilisa Jiménez-García’s critical review of 36 books for children and young adults written by authors of color. The articles selected for this issue are uniformly compelling and engaging, and it is clear that Dahlen and Halko took care in ensuring that they selected submissions that not only incorporated the theme of mirrors, windows, and sliding glass doors in meaningful ways but also prominently featured the scholars' \#OwnVoices identities. The result is that the articles here do more than deliver a commendable first undertaking for RDYL; they also help realize RDYL's mission to present work that might not be accepted or privileged in other academic journals.

RDYL followed “\#OwnVoices Scholars Respond to 'Mirrors, Windows, and Sliding Glass Doors"” with an unthemed second issue. As with the first issue, this one contains thoughtful and important articles examining different aspects of diversity in children's and young adult literature, including one that investigates depictions of the Partition of British India in children's picture books. However, the most well-known work to emerge from this issue is undoubtedly Katie Ishizuka and Ramón Stephens's provocative and well-researched "The Cat is Out of the Bag: Orientalism, AntiBlackness, and White Supremacy in Dr. Seuss's Children’s Books.” By analyzing the content of Seuss's children's books, Ishizuka and Stephens illuminate Seuss's problematic depictions of race throughout his career and call into question assertions that 1) questionable representations by Seuss were limited to his early work and did not seep into his children's books (many of which are fixtures in classroom and school libraries) and 2) The Sneetches and Horton Hears a Who! should be used to teach equality and tolerance. The study and article gained a great deal of attention in the popular media, with outlets including People.com and NPR reporting on the findings and speculating on what it means for Read Across America Day, which is on Seuss's birthday and is often used to celebrate his work, and for Seuss's legacy in general.

Another notable feature in RDYL's second issue is the section dedicated to youth activism. Guest edited by author and educator Breanna McDaniel, this section features different ways that young people have spoken up and participated in protests and movements such as Black Lives Matter and March for Our Lives. Two of the most intriguing selections here are the ones that allow adolescent participants to share their ideas and insights. In "The Day Tajon Got Shot: An Introduction,” McDaniel interviews Temil Whipple, Jonae Haynesworth, and Makiya Holmes, three of the ten young women, ages 12 to 15 , who collaborated to write the young adult novel The 
Day Tajon Got Shot, a young adult novel that considers what happens when a black teenager is the victim of police violence. The second article offers another approach to youth engagement, as Shelly K. Barger shares her story of organizing a walkout as part of the March of Our Lives after she was inspired by not just the shooting at Marjory Stoneman Douglas High School but also the one at Pulse nightclub. The inclusion of articles on youth activism told through the voices of the young people involved adds another dimension to the journal and allows RDYL to continue its efforts to "diversify... discussions regarding youth literature and media" and "provide space for emerging scholars and undervalued scholarship" (About This Journal).

RDYL opened its second volume (and most recent issue as of the time of writing this review) with the theme "Queer Futurities in Youth Literature." Guest edited by Angel Daniel Matos and John Michael Wargo, the issue centers on the depictions of queer theory in children's and young adult literature and media, "especially when it comes to assessing how youth literatures and media either reaffirm or pressure common approaches to queer futurities, and whether we can begin to theorize temporal models that are exclusive to the study of children's and YA aesthetic productions" (Matos and Wargo, 2019, p.11). The articles featured realize this goal, with authors tackling topics such as representations of queer virginity in the song "Bloom" and the young adult novel Symptoms of Being Human and the implications on queer futurities presented by When Everything Feels Like the Movies, which won Canada's 2014 Governor General's Award for Children's Literature to great controversy.

As with the earlier issues, this one offers a stimulating and distinctive way of considering diversity in books and media meant for children and adolescents. The focus on queer futurities lends itself to different angles on how these futurities are represented and what implications these depictions might have on readers. Furthermore, the articles demonstrate not just different ways to interpret queer futurities but also different ways of researching and writing about youth literature. For instance, Michelle Ann Abate's "Out of the Past: Aristotle and Dante Discover the Secrets of the Universe, the AIDS Crisis, and Queer Retrosity" deftly analyzes the historical context of the novel's 1980s setting and the implications that the novel ignores the AIDS crisis, one of the most prominent LGBTQ issues at the time. However, Abate goes further, reconsidering the novel's problematic omission of the AIDS crises and offering a nuanced alternative for how readers and scholars might interpret the absence of AIDS in the text. 
RDYL presents a unique and vital forum for different populations interested in diversity and representation in children's and young adult literature. This is due, in large part, to its interdisciplinary approach, which encourages people from interrelated fields such as education, literature, librarianship, and publishing to not only read the journal but also to have discussions and even collaborate on work related to diversity. Furthermore, RDYL's open-access platform democratizes the journal and the information therein by allowing anyone interested to read the articles without having to be part of an academic institution or to pay for the privilege. Consequently, RDYL can serve as a means of breaking down the silos that separate different populations so that stakeholders can work together toward a greater good.

Besides serving as a way to open up a dialogue among disparate parties, RDYL also presents a wealth of opportunities for people in academia. The most obvious use would be having articles or issues as part of a class reading list, especially for courses on literacy, children's and young adult literature, and library services. For instance, Ishizuka and Stephens's "The Cat is Out of the Bag: Orientalism, Anti-Blackness, and White Supremacy in Dr. Seuss's Children's Books” could provide the basis for valuable and constructive conversations regarding race in classic children's literature. Beyond content on diversity, RDYL can encourage all scholars, from undergraduate student to professors, to consider the different ways that researchers can study issues related to diversity. A prime example is Michelle H. Martin and J. Elizabeth Mills's “'Like Raindrops on Granite': A Dialogic Analysis of Full Cicada Moon as Crossover Scholarship," which can introduce and impart additional weight to crossover scholarship, thus encouraging graduate students and their advisors to take on research focused on diversity.

Research on Diversity in Youth Literature fills an important need in academic discourse today. As the United States becomes increasingly diverse and the world becomes more interconnected, it is vital that scholars examine representation in texts for children and young adults to ensure that these depictions are not just present but are also varied and genuine. RDYL offers both a means of honoring and disseminating this research and an outlet for researchers from diverse backgrounds to be part of the conversation. It is an exemplary journal that has already had an impact, and to the benefit of all who are invested in diversity in these books, it is sure to continue to shape and guide future discussion. 


\section{REFERENCES}

About This Journal. (n.d.). Retrieved from https://sophia.stkate.edu/rdyl/about.html

Cooperative Children's Book Center. (2019, July 5). Publishing Statistics on Children's/YA Books about People of Color and First/Native Nations and by People of Color and First/Native Nations Authors and Illustrators. Retrieved July 5, 2019, from Cooperative Children’s Book Center website: https://ccbc.education.wisc.edu/books/pcstats.asp

Ehrlich, H. (2017, March 30). The Diversity Gap in Children’s Book Publishing, 2017. Retrieved July 1, 2019, from Lee and Low Books: The Open Book Blogwebsite: https://blog.leeandlow.com/2017/03/30/the-diversity-gap-in-childrens-book-publishing$2017 /$

Halko, G. A., \& Dahlen, S. P. (2018). Editors' introduction. Research on Diversity in Youth Literature, 1(1), 1-5. Retrieved from https://sophia.stkate.edu/cgi/viewcontent.cgi?article=1002\&context=rdyl

Martin, M. H., \& Mills, J. E. (2018). "Like raindrops on granite”: A dialogic analysis of Full Circada Moon as crossover scholarship. Research on Diversity in Youth Literature, 1(1), 1-17. Retrieved from https://sophia.stkate.edu/cgi/viewcontent.cgi?article=1004\&context=rdyl

Matos, A. D., \& Wargo, J. M. (2019). Editors' introduction: Queer futurities in youth literature, media, and culture. Research on Diversity in Youth Literature, 2(1), 1-17. Retrieved from https://sophia.stkate.edu/cgi/viewcontent.cgi?article=1065\&context=rdyl

Slater, K. (2018). Editorial board statement for RDYL's inaugural issue. Research on Diversity in Youth Literature, 1(1), 1. Retrieved from https://sophia.stkate.edu/cgi/viewcontent.cgi?article=1001\&context=rdyl 
What is \#Disrupt Texts? (n.d.). Retrieved June 28, 2019, from \#Disrupt Texts website:

https://disrupttexts.org/lets-get-to-work/

TERRI SUICO is an associate professor of education at Saint Mary's College. She earned her EdD from Boston University School of Education and her MAT from Vanderbilt University. Her scholarly work has been included in several books. Most recently, her chapter on using Loving Vs. Virginia to teach and contextualize the struggle for marriage equality appeared in the book Breaking the Taboo with Young Adult Literature. She currently serves as the book review and interview editor for Study and Scrutiny: Research on Young Adult Literature. 